\title{
The equity premium in Brock's asset pricing model
}

\author{
Levent Akdeniz ${ }^{\mathrm{a}, *}, \mathrm{~W}$. Davis Dechert ${ }^{\mathrm{b}}$ \\ ${ }^{a}$ Faculty of Business Administration, Bilkent University, Turkey \\ ${ }^{\mathrm{b}}$ Department of Economics, University of Wisconsin, USA
}

Received 10 June 2005; accepted 13 June 2006

Available online 1 September 2006

\begin{abstract}
In this paper we combine dynamic programming methods with projection methods for solving stochastic growth models. As an application of these methods, we solve Brock's asset pricing model with a variety of parameterizations. We focused on finding parameterizations that result in an equity premium that is high relative to the variation in consumption.

We show (both analytically and numerically) that the equity premium can be higher in a production based asset pricing model than it is in the consumption based asset pricing model, even when the real output level is the same in both models.
\end{abstract}

(C) 2006 Elsevier B.V. All rights reserved.

JEL classification: G12; C63; D92

Keywords: Computational economics; Projection methods; Asset pricing models; Stochastic growth models

\section{Introduction}

The equity premium puzzle that was raised by Mehra and Prescott (1985) stems from the fact that for no reasonable parameterizations of the Lucas (1978) asset pricing model is the theoretical equity premium as large as the empirically observed

\footnotetext{
${ }^{*}$ Corresponding author.

E-mail addresses: akdeniz@ bilkent.edu.tr (L. Akdeniz),wdechert@ssc.wisc.edu (W.D. Dechert).
} 
equity premium. As they discovered, the Lucas model does not have sufficient flexibility to predict the extent of the equity premium. It does predict that there is an equity premium, but it is insufficiently large to be compatible with data. Brock (1982) asset pricing model is rich enough to predict a far more substantial equity premium. It gives pause for thought that if Mehra and Prescott had used Brock's model in their seminal article, the subsequent literature on the equity premium puzzle might have been less prolific and less contentious. ${ }^{1}$ Referring to the equity premium and the risk free rate puzzles, Kocherlakota (1996) points out that '... there is now a vast literature that seeks to resolve these two puzzles.' As Kocherlakota describes in that review of the literature, a number of alternate models ${ }^{2}$ have been developed to explain the equity premium puzzle. We do not criticize those models. ${ }^{3}$ Many of the effects that are captured in those models are important in the modeling of human behavior. Our point is that it is not necessary to change the assumption on preferences to get a higher equity premium. It is sufficient to include production processes in the model. ${ }^{4,5}$

In this paper we have two basic points to make. First, there are parameterizations of the Brock model that have equity premia that are: (1) more consistent with empirical evidence than those that were found by Mehra and Prescott in their

\footnotetext{
${ }^{1}$ They based their decision, in part, on Mehra (1984), and in part on their experience with production models. In Mehra and Prescott (1985) they write, 'If we had been successful in finding an economy which passed our not very demanding test, as we expected, we planned to add capital accumulation and production to the model using a variant of Brock's $(1979,1982) \ldots$ general equilibrium stationary structures and to perform additional tests.' Although they make no mention of the technical difficulties in solving Brock's model, it is likely that this was also a reason for their not having done so. Neither the algorithms nor the hardware used to produce the results in Akdeniz and Dechert (1997) were available then.

${ }^{2}$ Among others, are the models on habit formation, such as Constantinides (1990), Campbell and Cochrane (1999) and Boldrin et al. (2001), to cite a few. See also Campbell (2003) and the references there. McGrattan and Prescott (2001) show how taxes can account for both the growth in equity values as well as for the equity premium. In an earlier dynamic model of regulation and taxation, Brock and Turnovsky (1981) derived the impact of government policy on asset values. In a paper that has applications well beyond the equity premium puzzle, Weitzman (2004) argues that the modeling should be forward looking in the sense that ' $\ldots$ the correct interpretation requires not frequentist objective estimates of the past mean and variance, but rather Bayesian subjective estimates of the future mean and variance.' (Emphasis in the original.)

${ }^{3}$ Geweke (1999) does raise the point that 'The benefits of an analytically rigorous economic theory will be realized only when harnessed to the same high standards for measurement.' He found that 'The posterior distribution for the mean of the risk free rate and the equity premium supports values consistent with ... dynamic stochastic general equilibrium models designed to address this question.'

${ }^{4}$ In referring to Brock's asset pricing model, Black (1995) remarked, 'If we add non-separable utility, adjustment costs for moving capital from one sector to another, human capital, and a few other features, we will have a model of the kind I favor.' This kind of model would indeed include many useful components that would make the results more realistic. Nevertheless, as we show in this paper, including production alone is sufficient to get the size of the equity premium that Mehra and Prescott were looking for.

${ }^{5}$ Campbell (2003) makes the comment that 'Models with production also help one to move away from the common assumption that stock market dividends equal consumption ...' and he goes on to conclude that '... it will ultimately be more satisfactory to derive both dividends and consumption within a general equilibrium model.' This is, of course, what Brock does in his asset pricing model.
} 
solution of the Lucas asset pricing model ${ }^{6}$ and that are (2): consistent with empirical values for utility and production parameters. Second, the values of all relevant financial variables in the model are functions of the output level. ${ }^{7}$ The values of the equity premium that are reported in empirical research are averages over time which means that the values have been averaged over the business cycle. However, one of the strong results from the Brock asset pricing model is that one should find that the equity premium is much higher at the bottom of a business cycle than it is at the top of the business cycle. ${ }^{8}$

In Section 5 we present some scaling results that show, in part, why Brock's model with production leads to a higher equity premium than a consumption based model, or even a single firm model. What we show is that, along with systematic shocks, there must be idiosyncratic shocks that alter the marginal products of the firms differently from each other. ${ }^{9}$ Otherwise, as we show in Section 5 the model reduces to a one firm model, and the equity premium is comparable to those reported in Mehra and Prescott (1985) for their consumption based asset pricing model. In Section 4 we show how we model systematic and idiosyncratic shocks so that the (random) marginal products of the firms differ in each state.

\subsection{A parameterization of the Brock APM}

In Brock $(1979,1982)$ it is shown how the stochastic economic growth model can be used to solve for the asset prices in a production based economy. However, there is only one parameterization for which a closed form solution exists for this model, ${ }^{10}$ so we have to rely on numerical methods for solutions for the other cases. The advantage of numerical methods, as Judd (1995) points out, is that we can often solve for a much broader class of cases than is possible with analytical methods.

In this study we use that solution and explore the parameter space for solutions to the model that, to a certain extent, fit some of the stylized facts of asset markets. Many of the stylized facts (such as those that Cooley and Prescott, 1995 report) relate to economic growth. In our model there is no labor and no population to grow, so we examine those results that do not relate directly to issues of economic growth. In particular, the equity premium puzzle is not related to the growth of the economy.

\footnotetext{
${ }^{6}$ In that study the consumer's discount factor and risk aversion parameter were varied and the highest equity premium they found was $0.35 \%$. In our study we focus most of our attention on keeping the values of the discount factor and risk aversion parameter consistent with empirical results.

${ }^{7}$ This property was emphasized in Akdeniz and Dechert (1997) and Akdeniz (2000) where it was shown that the asset prices are a function of the output level.

${ }^{8}$ In the introduction to their paper, Campbell and Cochrane (1999) state, ' $\ldots$ standard business cycle models utterly fail to reproduce the level, variation, and cyclical co-movement of equity premia.' As we show in this paper, Brock's APM does in fact reproduce the cyclical co-movement of equity premia with the level of output.

${ }^{9}$ The same conclusion that idiosyncratic shocks have an impact was reported in Turnovsky and Bianconi (2005) and Saito (1998).

${ }^{10}$ The special case is for a logarithmic utility function, and Cobb-Douglas firms, where the value of the output elasticity (with respect to the input) is common to all firms.
} 
In this paper we explore the parameter space with a primary focus of presenting the results for values of the annual discount factor of $\beta$ ranging from 0.95 to 0.99 , and the relative risk aversion coefficient of $\gamma$ ranging from -1 to $-4 .^{11}$ These are typical values based on US data. ${ }^{12}$

In Section 5.4 we also compare the formulæ for the asset prices and equity premia in both the Brock and Lucas asset pricing models. One of the conclusions is that if the asset pricing functions and the investment functions are linear in the level of output, then there is no difference in the equity premia in the two models. However, as we show with our numerical results in Section 4, there are parameterizations of the Brock model for which the equity premia are higher than those of the Lucas model.

\section{The growth model}

In this section we borrow heavily from Brock (1979). The essential elements of the growth model are

$$
\begin{array}{cl}
V\left(y_{0}\right)=\max _{\left\{c_{t}, x_{i t}\right\}} & \mathrm{E}\left[\sum_{t=0}^{\infty} \beta^{t} u\left(c_{t}\right)\right] \\
\text { subject to: } & x_{t}=\sum_{i=1}^{N} x_{i t} \\
& y_{t+1}=\sum_{i=1}^{N} f_{i}\left(x_{i t}, \xi_{t}\right) \\
& c_{t}+x_{t}=y_{t} \\
& c_{t}, x_{i t} \geqslant 0 \\
& y_{0} \text { given, }
\end{array}
$$

where $\beta$ is the discount factor on future utility, $u$ the per period utility function of consumption, $c_{t}$ the consumption at date $t, y_{t}$ the output at date $t, x_{t}$ the capital stock at date $t, f_{i}$ the production function of process $i, x_{i t}$ the capital allocated to process $i$ at date $t, \xi_{t}$ the random shock.

For a description and interpretation of the model see Brock (1982). The main assumptions for this model are:

(A1) the utility function, $u$, is concave, increasing and twice continuously differentiable;

(A2) the production functions, $f_{i}$, are concave, increasing, twice continuously differentiable, and satisfy the Inada conditions;

\footnotetext{
${ }^{11}$ In our work we use $u(c)=\left(c^{\gamma}-1\right) / \gamma$ for the utility function. In some of the studies cited, it is specified as $u(c)=\left(c^{1-\gamma}-1\right) /(1-\gamma)$, and so our value of $\gamma=-1$ would correspond to $\gamma=2$ in those models.

${ }^{12}$ Campbell and Cochrane (1999) use a value of $\gamma=2.00$ (which would correspond to a value of -1.00 in our formulation). Since there is no universal value for the relative risk aversion parameter, we present results for several values of $\gamma$.
} 
(A3) the stochastic process $\left\{\xi_{t}\right\}$ is independent and identically distributed;

The first order conditions ${ }^{13}$ for the intertemporal maximization are

$$
u^{\prime}\left(c_{t-1}\right)=\beta \mathrm{E}_{t-1}\left[u^{\prime}\left(c_{t}\right) f_{i}^{\prime}\left(x_{i t}, \xi_{t}\right)\right]
$$

and the transversality condition is

$$
\lim _{t \rightarrow \infty} \beta^{t} \mathrm{E}_{0}\left[u^{\prime}\left(c_{t}\right) x_{t}\right]=0 .
$$

Eq. (2.7) is the one that is used to derive a numerical solution to the growth model. Since the problem given by Eqs. (2.1)-(2.6) is time stationary the optimal levels of $c_{t}$, $x_{t}$, and $x_{i t}$ are functions of the output level $y_{t}$, and can be written as

$$
c_{t}=c\left(y_{t}\right), \quad x_{t}=h\left(y_{t}\right), \quad x_{i t}=h_{i}\left(y_{t}\right) .
$$

The first two functions in Eq. (2.9) can be expressed in terms of the individual firm investment functions

$$
\begin{aligned}
& h(y)=\sum_{i=1}^{N} h_{i}(y), \\
& c(y)=y-h(y) .
\end{aligned}
$$

Given these functions, one can then define next period's output, given the current level of output, $y$, and the shock, $\xi$

$$
Y(y, \xi)=\sum_{i=1}^{N} f_{i}\left(h_{i}(y), \xi\right) .
$$

A numerical solution to this problem are policy functions (2.9) that satisfy

$$
u^{\prime}(c(y))=\beta \mathrm{E}\left[u^{\prime}(c(Y(y, \xi))) f_{i}^{\prime}\left(h_{i}(Y(y, \xi)), \xi\right)\right]
$$

for $i=1, \ldots, N$ and for all $y$ and for which the transversality condition (2.8) holds. Fortunately, the transversality condition does not have to be directly verified. A bounded solution to Eq. (2.13) satisfies the transversality condition. ${ }^{14}$ Further details are in Akdeniz and Dechert (1997).

\section{An asset pricing model}

The asset pricing model in Brock (1982) has its roots in the models of Brock and Mirman (1972) and Lucas (1978). In particular, Brock also solves for the rational expectations equilibrium. The difference between the Brock (1982) and Lucas (1978)

\footnotetext{
${ }^{13}$ We assume that $x_{i t}>0$. If not then the Kuhn-Tucker type conditions in Brock (1979) must be used. In our numerical studies we used functional forms that include a Cobb-Douglas term, so our assumption is satisfied.

${ }^{14}$ See Judd $(1992,1998)$ for the solution to the one firm growth model and the argument about the transversality condition.
} 
models is that former includes production. By incorporating the shocks in with the production processes, Brock's model has the sources of uncertainty in the asset prices directly tied to economic fluctuations in output levels (and hence in profits).

There is one representative consumer whose preferences are given in Eq. (2.1). There are $N$ different firms. Firms rent capital from the consumers at the rate $r_{i t}$ to maximize their profits

$$
\pi_{i, t+1}=f_{i}\left(x_{i t}, \xi_{t}\right)-r_{i t} x_{i t} .
$$

Each firm rents capital given $\xi_{t}$. Here $r_{i t}$ denotes the interest rate on capital in industry $i$ at date $t$ and is determined within the model. Asset shares are normalized so that there is one perfectly divisible equity share for each firm. Ownership of the share in firm $i$ at date $t$ entitles the consumer to the firms profits at date $t$. It is also assumed (as in Lucas, 1978) that the optimum levels of asset prices, capital, consumption and output form a rational expectations equilibrium.

\subsection{The model}

The representative consumer takes asset prices, profits and rents as given and solves the following problem:

$$
\max \mathrm{E}\left[\sum_{t=0}^{\infty} \beta^{t} u\left(c_{t}\right)\right]
$$

subject to:

$$
\begin{aligned}
& c_{t}+x_{t}+P_{t} \cdot Z_{t} \leqslant \pi_{t} \cdot Z_{t-1}+P_{t} \cdot Z_{t-1}+r_{t-1} \cdot x_{t-1} \\
& c_{t}, Z_{t}, x_{i t} \geqslant 0 \\
& r_{i t}=f_{i}^{\prime}\left(x_{i t}, \xi_{t}\right) \\
& \pi_{i t}=f_{i}\left(x_{i, t-1}, \xi_{t-1}\right)-f_{i}^{\prime}\left(x_{i, t-1}, \xi_{t-1}\right) x_{i, t-1},
\end{aligned}
$$

where $P_{i t}$ is the price of one share of firm $i$ at date $t, Z_{i t}$ the number of shares of firm $i$ owned at date $t, \pi_{i t}$ the profits of firm $i$ at date $t$.

The details of the model are in Brock (1982). The first order conditions are

$$
P_{i t} u^{\prime}\left(c_{t}\right)=\beta \mathrm{E}_{t}\left[u^{\prime}\left(c_{t+1}\right)\left(\pi_{i, t+1}+P_{i, t+1}\right)\right]
$$

and

$$
u^{\prime}\left(c_{t}\right)=\beta \mathrm{E}_{t}\left[u^{\prime}\left(c_{t+1}\right) f_{i}^{\prime}\left(x_{i, t+1}, \xi_{t+1}\right)\right]
$$

from which we get the prices for the assets. In addition the transversality conditions

$$
\begin{aligned}
& \lim _{t \rightarrow \infty} \beta^{t} \mathrm{E}_{0}\left[u^{\prime}\left(c_{t}\right) \sum_{i=1}^{N} P_{i t} Z_{i t}\right]=0, \\
& \lim _{t \rightarrow \infty} \beta^{t} \mathrm{E}_{0}\left[u^{\prime}\left(c_{t}\right) x_{t}\right]=0
\end{aligned}
$$

are needed to fully characterize the optimum. Brock (1979) shows that there is a duality between the growth model (2.1)-(2.6) and the asset pricing model (3.2)-(3.5), 
and that the solution to the growth model is also the solution to the asset pricing model. Once the growth model is solved, the asset pricing functions can be solved for by Eq. (3.6). As for the transversality condition, Judd (1992) points out that it implies that we are looking for the bounded solution ${ }^{15}$ to the growth model.

Other assets can be included in this model. Assets that are in zero net supply in equilibrium do not affect the real side of the model, and so the solution does not change. For example, we can introduce one period discount bonds into the model. If the bond pays $\$ 1$ (with probability one) at date $t+1$, then the equilibrium price of the bond, $B_{t, t+1}$, at date $t$ must satisfy

$$
u^{\prime}\left(c_{t}\right) B_{t, t+1}=\beta \mathrm{E}_{t}\left[u^{\prime}\left(c_{t+1}\right)\right]
$$

or

$$
B_{t, t+1}=\frac{\beta \mathrm{E}_{t}\left[u^{\prime}\left(c_{t+1}\right)\right]}{u^{\prime}\left(c_{t}\right)} .
$$

This, then, defines the one period risk free rate of return in period $t$ as $1 / B_{t, t+1}$. In similar fashion we can introduce an $n$ period discount bond that pays $\$ 1$ (with probability one) at date $t+n .^{16}$

Since (in equilibrium) there is one share of each asset, the equally weighted market portfolio is

$$
M_{t}=\sum_{i=1}^{N} P_{i t}
$$

and the dividends (profits) are

$$
\pi_{t}=\sum_{i=1}^{N} \pi_{i t} .
$$

Define the return on each asset by

$$
R_{i t}=\frac{p_{i, t+1}+\pi_{i, t+1}}{p_{i t}}
$$

and the (equally weighted) return on the market portfolio by

$$
R_{M t}=\frac{M_{t+1}+\pi_{t+1}}{M_{t}} .
$$

From the first order condition (3.6), the return on each asset satisfies

$$
u^{\prime}\left(c_{t}\right)=\beta \mathrm{E}\left[u^{\prime}\left(c_{t+1}\right) R_{i t}\right]
$$

which is the efficiency condition from the growth model. By summing Eq. (3.6), we get that the return on the market portfolio satisfies

$$
u^{\prime}\left(c_{t}\right)=\beta \mathrm{E}\left[u^{\prime}\left(c_{t+1}\right) R_{M t}\right]
$$

\footnotetext{
${ }^{15}$ The optimal solution remains in a bounded interval: $0<a<y_{t}<b<\infty$ for all $t$.

${ }^{16}$ In an analogous way one can also derive the price of an Arrow-Debreu security, i.e., an asset that pays $\$ 1$ if state $i$ occurs at date $t$ and $\$ 0$ otherwise.
} 
and so it is efficient. (This is one of the hypotheses of the CAPM, which in this model is a consequence of the optimizing behavior of the consumer. ${ }^{17}$ Now define the profit and output functions by

$$
\begin{aligned}
\pi_{i}(y, \xi) & =f_{i}\left(h_{i}(y), \xi\right)-h_{i}(y) f_{i}^{\prime}\left(h_{i}(y), \xi\right), \\
Y(y, \xi) & =\sum_{i=1}^{n} f_{i}\left(h_{i}(y), \xi\right)
\end{aligned}
$$

and the asset pricing functions by

$$
p_{i}(y) u^{\prime}(c(y))=\beta \mathrm{E}\left[u^{\prime}(c(Y(y, \xi)))\left(p_{i}(Y(y, \xi))+\pi_{i}(y, \xi)\right)\right]
$$

for $i=1, \ldots, n$. Once we have the pricing functions ${ }^{18}$ we next define the return functions

$$
\begin{aligned}
& R_{i}(y, \xi)=\frac{p_{i}(Y(y, \xi))+\pi_{i}(y, \xi)}{p_{i}(y)}, \\
& R_{M}(y, \xi)=\frac{\sum_{i=1}^{n}\left[p_{i}(Y(y, \xi))+\pi_{i}(y, \xi)\right]}{\sum_{i=1}^{n} p_{i}(y)}
\end{aligned}
$$

as well as the one period risk free bond price

$$
B(y)=\frac{\beta \mathrm{E}\left[u^{\prime}(c(Y(y, \xi)))\right]}{u^{\prime}(c(y))} .
$$

As these formulæ make clear, the expected return on assets, $\mathrm{E}\left[R_{i}(y, \xi)\right]$, the expected return on the (equally weighted) market portfolio, $\mathrm{E}\left[R_{M}(y, \xi)\right]$, and the bond price, $B(y)$, are all functions of the output level, $y$. The equity premium in this model is given by

$$
e(y)=\mathrm{E}\left[R_{M}(y, \xi)\right]-\frac{1}{B(y)} .
$$

In order to study the term structure of interest rates in this model define the following recursion:

$$
\begin{aligned}
& G_{0}(y)=u^{\prime}(c(y)), \\
& G_{n+1}(y)=\mathrm{E}\left[u^{\prime}(c(Y(y, \xi))) G_{n}(Y(y, \xi))\right], \quad n=0,1, \ldots .
\end{aligned}
$$

Then the $n$ period risk free bond price when the output level is $y$ is

$$
\frac{G_{n}(y)}{u^{\prime}(c(y))} \text {. }
$$

In the next section we will explore the nature of the relationship of these functions in terms of the output level, $y$.

\footnotetext{
${ }^{17}$ See Akdeniz and Dechert (1997) and Akdeniz (2000) for more details on this issue.

${ }^{18}$ Solving Eq. (3.13) is easier than it might appear: these equations are linear in the functions $p_{i}$. The details are in Akdeniz and Dechert (1997).
} 


\section{A numerical solution}

Except for a very special case of the utility and production functions, there is no closed form solution for the optimal investment functions. ${ }^{19}$ In order to analyze the properties of the solutions to the asset pricing model we must use numerical techniques instead. Akdeniz and Dechert (1997) report the technical details of the numerical solution which we will not repeat here. ${ }^{20}$ In this study we use that solution and explore the parameter space for solutions to the model that, to a certain extent, fit some of the stylized facts of asset markets. Our primary focus will be on the equity premium and the term structure of interest rates that come out of the Brock asset pricing model.

Akdeniz (2000) and Akdeniz and Dechert (1997) showed that CAPM results do hold in the model, but with the proviso that they depend on the level of output. ${ }^{21}$ I.e., an asset's beta is not constant over time, but fluctuates with the level of output. Furthermore, at each level of output the market portfolio (which is efficient in this model) $i s$ on the security market line (at that level of output).

In Section 4.3 we report the results of simulations using the numerical solution for the model. In keeping with the results found by Akdeniz and Dechert, one of the important features to note is that the equity premium sharply depends on the level of output. In the tables, for each value of $\gamma$ and $\beta$ there are five values of the equity premium which, reading down the table, occur for low, below average, average, above average and high output levels. ${ }^{22}$

\subsection{Computational details}

We use the projection method ${ }^{23}$ to solve Eq. (2.13) for the coefficients of the policy functions $^{24}$

$$
h_{i}(y)=\sum_{j=0}^{m} a_{i j} T_{j}(y),
$$

where $T_{j}(y)$ is the $i$ th Chebyshev polynomial shifted to the interval which is the support of the invariant measure, $\left[y_{\min }, y_{\max }\right]$. One of the steps is to use Newton's method to solve for the coefficients, $\left\{a_{i j}\right\}$. Since Newton's method is only locally

\footnotetext{
${ }^{19}$ The special case is for a logarithmic utility function, $u(c)=\log (c)$, and for Cobb-Douglas firms, $f_{i}\left(x, \xi_{i}\right)=\xi_{i} x^{\alpha}$, where the value of $\alpha$ is common to all firms. In this case the optimal investment policy functions are linear in output, $\hat{x}_{i}(y)=\gamma_{i} y$.

${ }^{20}$ Basically, Eq. (2.13) is solved for the policy functions, $h_{i}(y)$, and then Eq. (3.13) is solved for the pricing functions, $p_{i}(y)$.

${ }^{21}$ As pointed out by Campbell and Cochrane (1999), ‘... the slope of the conditional mean-variance frontier ... changes through time with a business cycle pattern ...' This is precisely what Akdeniz (2000) shows in the context of Brock's APM.

${ }^{22}$ The tables are based on the long run distribution of output. The levels used in the tables are the 10, 30, 50,70 and 90 th percentiles.

${ }^{23}$ See Akdeniz and Dechert (1997) for complete details. Also see Judd (1992) and Judd (1998) for a further description of the technique as applied to problems in economic analysis.

${ }^{24}$ Actually, we are solving for polynomial approximations to the policy functions.
} 


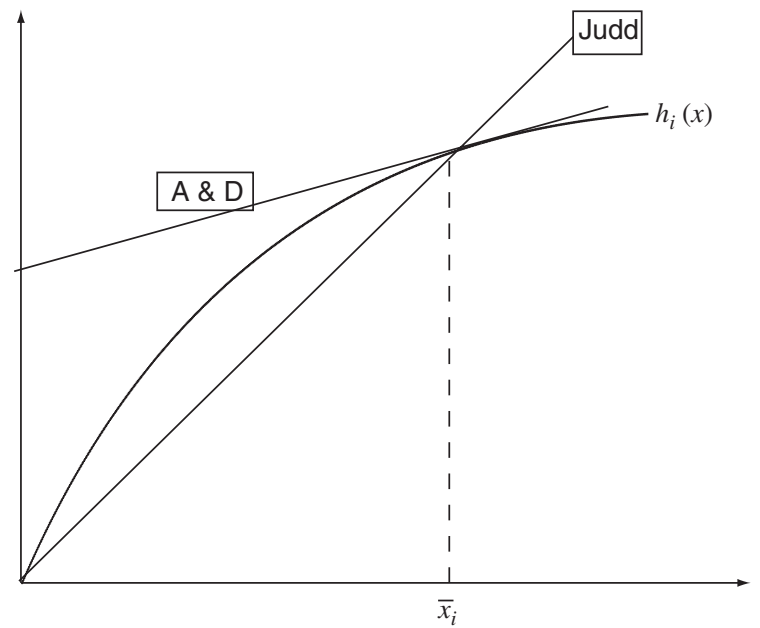

Fig. 1. Initialization of $\sum_{j=0}^{m} a_{i j} T_{j}(y)$.

convergent, we need a good initial set of values for these coefficients. In Judd (1992) good results were obtained by choosing a linear approximation that passes through the origin and the steady state. ${ }^{25}$ In the model in this paper we are dealing with the multi firm stochastic case, and need an alternative procedure. We chose to first create a deterministic model by taking the expected value of the firm's production functions. For this deterministic model, we can readily solve for the steady state levels of capital for each firm. It turns out that the linear approximations of the policy functions which passes through the origin and the steady states are not good enough in general to get Newton's method to converge. So, by using the value function for this deterministic case, we also computed the derivative of the policy functions at the steady state and used linear approximations at the steady state as an initial point for the Newton routine. See Fig. 1 for a pictorial representation of this method. As long as the values $y_{\min }$ and $y_{\max }$ are reasonably close to the deterministic steady state, the Newton method converges for this initialization. The values of $y_{\min }$ and $y_{\max }$ then have to be determined by trial and error. ${ }^{26}$

\subsection{Systematic and idiosyncratic shocks}

For firm production functions we use Cobb-Douglas functional forms with depreciation. Total output in state $s$ and period $t$ and is

$$
y_{s, t+1}=\sum_{i=1}^{n}\left[\theta_{i s} x_{i t}^{\alpha_{i s}}+\left(1-\delta_{i s}\right) x_{i t}\right]
$$

\footnotetext{
${ }^{25}$ In that article, a deterministic growth model with a single firm was analyzed.

${ }^{26} \mathrm{In}$ order to determine the support of the invariant distribution of output we need to solve $y=$ $\min _{\xi} Y(y, \xi)$ and $y=\max _{\xi} Y(y, \xi)$ for the crossing points on the $45^{\circ}$ line. See Eq. (2.12) for the definition of $Y(y, \xi)$.
} 


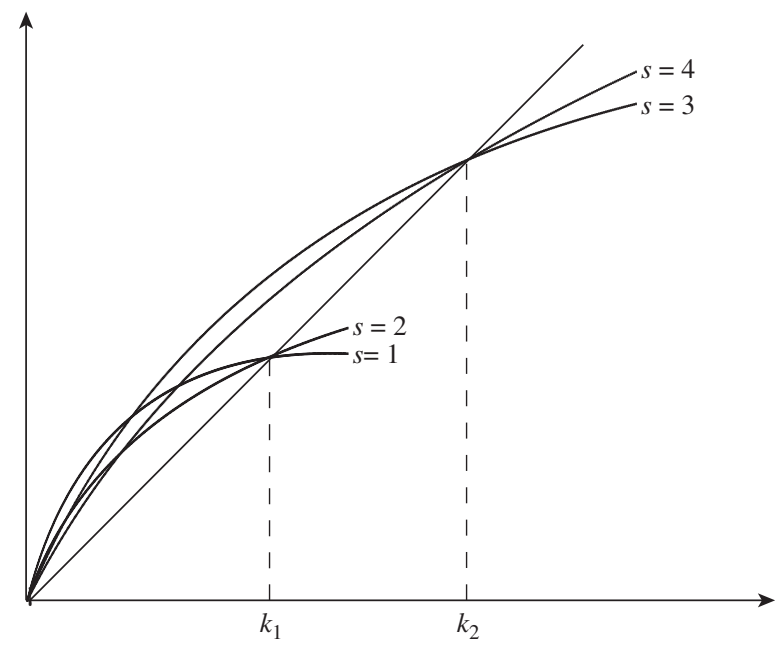

Fig. 2. $\Omega_{1}=\{1,2\}, \Omega_{2}=\{3,4\}$.

where $n$ is the number of firms. For the numerical work below, we took the depreciation terms to be deterministic, and so

$$
\delta_{i s}=\delta_{i}, \quad i=1, \ldots, n .
$$

In order to model both systematic shocks as well as idiosyncratic shocks we constructed the $\left(\alpha_{i s}, \theta_{i s}\right)$ parameters as follows. First, construct a partition of the state space, $\left\{\Omega_{j}\right\}$ for $j=1, \ldots, m$, and select capital levels, $k_{1}<k_{2}<\cdots<k_{m}$, one for each partition. Next, select values of $\alpha_{i s}$. These can be chosen at random, or they can be chosen to fit a pattern based on stylized facts. Then the parameters $\theta_{i s}$ are chosen so that

$$
\theta_{i s}=\delta_{i} k_{j}^{1-\alpha_{i s}}, \quad s \in \Omega_{j}
$$

This implies that for all the firms, $i$,

$$
\theta_{i s} k_{j}^{\alpha_{i s}}+\left(1-\delta_{i}\right) k_{j}=k_{j} \quad \forall s \in \Omega_{j}
$$

holds for all $j=1, \ldots, m$. A visual example of the effect of this parameterization is in Fig. 2.

\subsection{Numerical results}

In this section we will present some results from simulation studies of the solution to Brock's asset pricing model with various parameterizations. The examples will show that there are values of the parameters of the model that give values of excess returns (at the median level of output) in excess of $5 \%$. 
Table 1

Parameter values of the three firms

\begin{tabular}{lllllll}
\hline State & $\alpha_{1}$ & $\alpha_{2}$ & $\alpha_{3}$ & $\theta_{1}$ & $\theta_{2}$ & $\theta_{3}$ \\
\hline 1 & 0.200 & 0.204 & 0.204 & 0.268 & 0.178 & 0.351 \\
2 & 0.420 & 0.414 & 0.414 & 0.651 & 0.439 & 0.868 \\
3 & 0.392 & 0.378 & 0.378 & 0.235 & 0.158 & 0.312 \\
4 & 0.352 & 0.495 & 0.495 & 0.770 & 0.360 & 0.710 \\
5 & 0.448 & 0.457 & 0.357 & 0.226 & 0.149 & 0.316 \\
6 & 0.348 & 0.357 & 0.557 & 0.779 & 0.506 & 0.609 \\
7 & 0.548 & 0.457 & 0.457 & 0.211 & 0.149 & 0.295 \\
8 & 0.448 & 0.557 & 0.557 & 0.608 & 0.308 & 0.609 \\
\hline
\end{tabular}

Table 2

Equity premia at $\gamma=-1.0, \beta=0.95, \sigma_{c}=0.0927$

\begin{tabular}{lllll}
\hline $\mathrm{P}\{Y<y\}(\%)$ & Market $(\%)$ & Firm 1 $(\%)$ & Firm 2 $(\%)$ & Firm 3 $(\%)$ \\
\hline 10 & 5.37 & 5.56 & 5.62 & 5.04 \\
30 & 3.83 & 3.95 & 4.04 & 3.59 \\
50 & 3.17 & 3.26 & 3.36 & 2.98 \\
70 & 2.75 & 2.82 & 2.93 & 2.58 \\
90 & 2.21 & 2.26 & 2.37 & 2.08 \\
\hline
\end{tabular}

Table 3

Equity premia at $\gamma=-1.0, \beta=0.97, \sigma_{c}=0.0961$

\begin{tabular}{lllll}
\hline $\mathrm{P}\{Y<y\}(\%)$ & Market $(\%)$ & Firm 1 $(\%)$ & Firm 2(\%) & Firm 3 $(\%)$ \\
\hline 10 & 4.73 & 4.82 & 4.9 & 4.55 \\
30 & 4.17 & 4.24 & 4.32 & 4.03 \\
50 & 3.46 & 3.5 & 3.58 & 3.34 \\
70 & 2.55 & 2.59 & 2.66 & 2.46 \\
90 & 1.4 & 1.42 & 1.48 & 1.34 \\
\hline
\end{tabular}

First, we present some results that show that the equity premium can be quite large, even for some fairly reasonable values of the parameters. In the examples, the parameter values are for a model with three firms and eight states of uncertainty. For these examples, the range of utility parameters are $\beta=0.95,0.97,0.99$, and $\gamma=-1.0,-2.0,-3.0,-4.0$ (Table 1).

The resulting values of the equity premium are listed in Tables $2-14 .{ }^{27}$ The first column in the tables are levels of the invariant distribution of output. The second column is the excess return on the market portfolio, and the remaining columns are the excess returns on the individual firm shares. Each table caption shows the

\footnotetext{
${ }^{27}$ See Tables 15 and 16 for some corresponding risk free rates in the columns labeled $t=1$.
} 
Table 4

Equity premia at $\gamma=-1.0, \beta=0.99, \sigma_{c}=0.0755$

\begin{tabular}{lllll}
\hline $\mathrm{P}\{Y<y\}(\%)$ & Market $(\%)$ & Firm 1 $(\%)$ & Firm 2 $(\%)$ & Firm 3 $(\%)$ \\
\hline 10 & 3.41 & 3.43 & 3.47 & 3.35 \\
30 & 2.68 & 2.69 & 2.73 & 2.64 \\
50 & 2.21 & 2.21 & 2.25 & 2.17 \\
70 & 1.77 & 1.78 & 1.81 & 1.74 \\
90 & 1.29 & 1.29 & 1.32 & 1.27 \\
\hline
\end{tabular}

Table 5

Equity premia at $\gamma=-2.0, \beta=0.95, \sigma_{c}=0.0815$

\begin{tabular}{lllll}
\hline $\mathrm{P}\{Y<y\}(\%)$ & Market (\%) & Firm 1 (\%) & Firm 2 (\%) & Firm 3 (\%) \\
\hline 10 & 7.85 & 8.13 & 8.28 & 7.35 \\
30 & 6 & 6.17 & 6.33 & 5.66 \\
50 & 4.95 & 5.07 & 5.23 & 4.68 \\
70 & 3.89 & 3.97 & 4.12 & 3.68 \\
90 & 2.65 & 2.7 & 2.83 & 2.5 \\
\hline
\end{tabular}

Table 6

Equity premia at $\gamma=-2.0, \beta=0.97, \sigma_{c}=0.0708$

\begin{tabular}{lllll}
\hline $\mathrm{P}\{Y<y\}(\%)$ & Market $(\%)$ & Firm 1 $(\%)$ & Firm 2 $(\%)$ & Firm 3 (\%) \\
\hline 10 & 6.37 & 6.49 & 6.64 & 6.09 \\
30 & 4.87 & 4.94 & 5.08 & 4.68 \\
50 & 3.91 & 3.96 & 4.09 & 3.77 \\
70 & 2.99 & 3.02 & 3.13 & 2.87 \\
90 & 2.06 & 2.07 & 2.17 & 1.98 \\
\hline
\end{tabular}

Table 7

Equity premia at $\gamma=-2.0, \beta=0.99, \sigma_{c}=0.0632$

\begin{tabular}{lllll}
\hline $\mathrm{P}\{Y<y\}(\%)$ & Market $(\%)$ & Firm 1 (\%) & Firm 2 (\%) & Firm 3 (\%) \\
\hline 10 & 5.11 & 5.14 & 5.22 & 5.02 \\
30 & 4.09 & 4.11 & 4.17 & 4.03 \\
50 & 3.37 & 3.38 & 3.44 & 3.32 \\
70 & 2.6 & 2.6 & 2.65 & 2.56 \\
90 & 1.65 & 1.66 & 1.69 & 1.63 \\
\hline
\end{tabular}

particular values of $\gamma$ and $\beta$, and also the value of the standard deviation of consumption, $\sigma_{c}$.

Typical results for the term structure of interest rates are given in Tables 15 and 16. Note that the interest rates depend on the output level, with high interest rates 
Table 8

Equity premia at $\gamma=-3.0, \beta=0.95, \sigma_{c}=0.0717$

\begin{tabular}{lcccc}
\hline $\mathrm{P}\{Y<y\}(\%)$ & Market $(\%)$ & Firm 1 $(\%)$ & Firm 2 (\%) & Firm 3 $(\%)$ \\
\hline 10 & 10.3 & 10.7 & 10.9 & 9.62 \\
30 & 7.81 & 8.02 & 8.25 & 7.38 \\
50 & 6.29 & 6.42 & 6.63 & 5.97 \\
70 & 4.69 & 4.78 & 4.96 & 4.46 \\
90 & 2.8 & 2.84 & 3 & 2.64 \\
\hline
\end{tabular}

Table 9

Equity premia at $\gamma=-3.0, \beta=0.97, \sigma_{c}=0.0626$

\begin{tabular}{lllll}
\hline $\mathrm{P}\{Y<y\}(\%)$ & Market $(\%)$ & Firm 1 $(\%)$ & Firm 2(\%) & Firm 3 (\%) \\
\hline 10 & 8.77 & 8.95 & 9.18 & 8.36 \\
30 & 6.57 & 6.66 & 6.86 & 6.32 \\
50 & 5.15 & 5.21 & 5.38 & 4.97 \\
70 & 3.67 & 3.71 & 3.84 & 3.54 \\
90 & 2.27 & 2.29 & 2.39 & 2.19 \\
\hline
\end{tabular}

Table 10

Equity premia at $\gamma=-3.0, \beta=0.97, \sigma_{c}=0.0677, \delta_{i}+0.01$

\begin{tabular}{lcccc}
\hline $\mathrm{P}\{Y<y\}(\%)$ & Market $(\%)$ & Firm 1 $(\%)$ & Firm 2(\%) & Firm 3 (\%) \\
\hline 10 & 10.4 & 10.7 & 10.9 & 10 \\
30 & 8.33 & 8.44 & 8.62 & 8.06 \\
50 & 6.08 & 6.15 & 6.29 & 5.91 \\
70 & 3.69 & 3.73 & 3.84 & 3.57 \\
90 & 1.87 & 1.89 & 1.97 & 1.8 \\
\hline
\end{tabular}

Table 11

Equity premia at $\gamma=-3.0, \beta=0.99, \sigma_{c}=0.0557$

\begin{tabular}{lllll}
\hline $\mathrm{P}\{Y<y\}(\%)$ & Market $(\%)$ & Firm 1 $(\%)$ & Firm 2(\%) & Firm 3 $(\%)$ \\
\hline 10 & 7.34 & 7.38 & 7.5 & 7.2 \\
30 & 5.76 & 5.78 & 5.87 & 5.68 \\
50 & 4.55 & 4.56 & 4.63 & 4.49 \\
70 & 3.16 & 3.17 & 3.22 & 3.12 \\
90 & 1.68 & 1.68 & 1.72 & 1.66 \\
\hline
\end{tabular}

associated with low output levels, and low rates (negative) with high levels. The one period interest rates are the risk free rates that are used to measure the equity premium. 
Table 12

Equity premia at $\gamma=-4.0, \beta=0.95, \sigma_{c}=0.0664$

\begin{tabular}{lcccc}
\hline $\mathrm{P}\{Y<y\}(\%)$ & Market $(\%)$ & Firm 1 $(\%)$ & Firm 2 $(\%)$ & Firm 3 $(\%)$ \\
\hline 10 & 12.2 & 12.7 & 13 & 11.4 \\
30 & 9.85 & 10.1 & 10.4 & 9.32 \\
50 & 7.95 & 8.11 & 8.35 & 7.58 \\
70 & 5.51 & 5.59 & 5.78 & 5.27 \\
90 & 2.7 & 2.73 & 2.88 & 2.57 \\
\hline
\end{tabular}

Table 13

Equity premia at $\gamma=-4.0, \beta=0.97, \sigma_{c}=0.0517$

\begin{tabular}{lcccc}
\hline $\mathrm{P}\{Y<y\}(\%)$ & Market $(\%)$ & Firm 1 $(\%)$ & Firm 2 $(\%)$ & Firm 3 (\%) \\
\hline 10 & 11.5 & 11.5 & 11.9 & 11.4 \\
30 & 7.25 & 7.23 & 7.46 & 7.14 \\
50 & 4.53 & 4.79 & 4.97 & 4.03 \\
70 & 4.71 & 4.59 & 4.75 & 4.81 \\
90 & 3.28 & 3.16 & 3.28 & 3.39 \\
\hline
\end{tabular}

Table 14

Equity premia at $\gamma=-4.0, \beta=0.99, \sigma_{c}=0.0514$

\begin{tabular}{lllll}
\hline $\mathrm{P}\{Y<y\}(\%)$ & Market $(\%)$ & Firm 1 $(\%)$ & Firm 2 $(\%)$ & Firm 3 (\%) \\
\hline 10 & 9.14 & 9.19 & 9.35 & 8.97 \\
30 & 7.53 & 7.55 & 7.67 & 7.43 \\
50 & 5.95 & 5.96 & 6.05 & 5.87 \\
70 & 3.95 & 3.95 & 4.01 & 3.9 \\
90 & 1.7 & 1.7 & 1.74 & 1.67 \\
\hline
\end{tabular}

Figs. 3-14, show the consumption levels for a simulation of the model for 120 periods. Note in both the tables and the figures how the standard deviation of consumption, $\sigma_{c}$, falls as $\gamma$ decreases, while the equity premium increases. ${ }^{28}$

\subsection{Comparative dynamics}

The impact of depreciation on the results can be substantial. For the three firm model above with depreciation levels increased by $1 \%$ for each firm in each state we get in increase in the equity premium at all levels of output. The results are in Table 10 and should be compared with the results in Table 9. As can be seen from

\footnotetext{
${ }^{28}$ This is of course a standard observation: as the consumer becomes increasingly risk averse, he smooths intertemporal consumption more and demands higher rates of return on risky assets.
} 
Table 15

Term structure at $\gamma=-2.0, \beta=0.97$

\begin{tabular}{lccc}
\hline $\mathrm{P}\{Y<y\}(\%)$ & $t=1(\%)$ & $t=2(\%)$ & $t=3(\%)$ \\
\hline 10 & 5.28 & 10.9 & 16.9 \\
30 & 1.85 & 4.05 & 6.56 \\
50 & -0.297 & -0.11 & 0.474 \\
70 & -1.85 & -3.2 & -4.12 \\
90 & -2.83 & -5.41 & -7.69 \\
\hline
\end{tabular}

Table 16

Term structure at $\gamma=-3.0, \beta=0.97$

\begin{tabular}{lccc}
\hline $\mathrm{P}\{Y<y\}(\%)$ & $t=1(\%)$ & $t=2(\%)$ & $t=3(\%)$ \\
\hline 10 & 4.93 & 10.2 & 15.8 \\
30 & 1.15 & 2.65 & 4.48 \\
50 & -1.32 & -2.05 & -2.33 \\
70 & -2.89 & -5.21 & -7.04 \\
90 & -3.22 & -6.34 & -9.24 \\
\hline
\end{tabular}

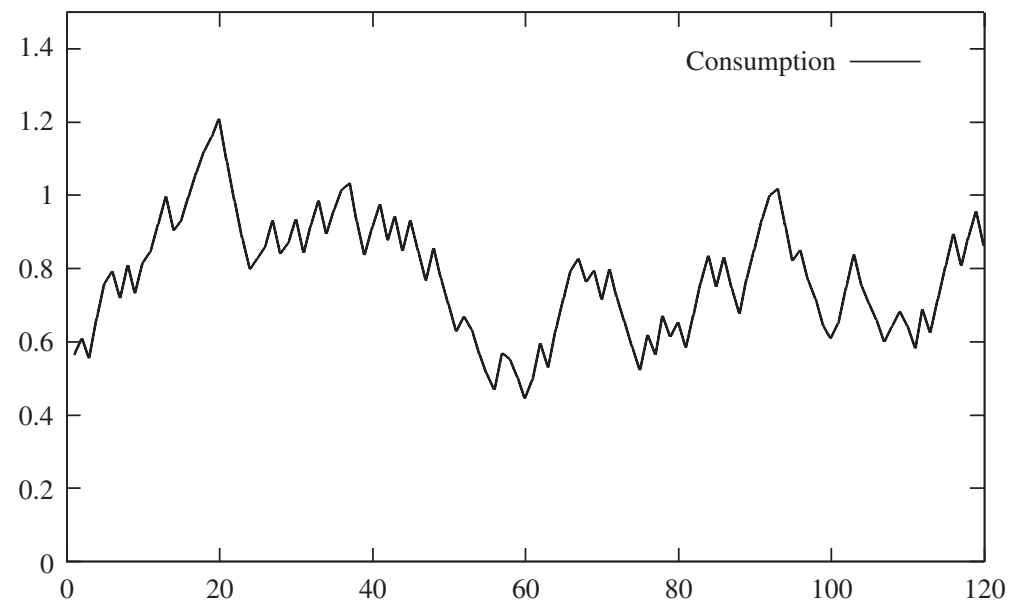

Fig. 3. Consumption at $\gamma=-1.0, \beta=0.95$.

these results, a change in depreciation has a substantial impact on the equity premium. Arguably, in the US economy depreciation rates have increased in the past 20 years. There is more rapid replacement of high technology capital which has become an ever increasing proportion of the US capital stock. This is certainly one of the testable hypotheses of this model. 


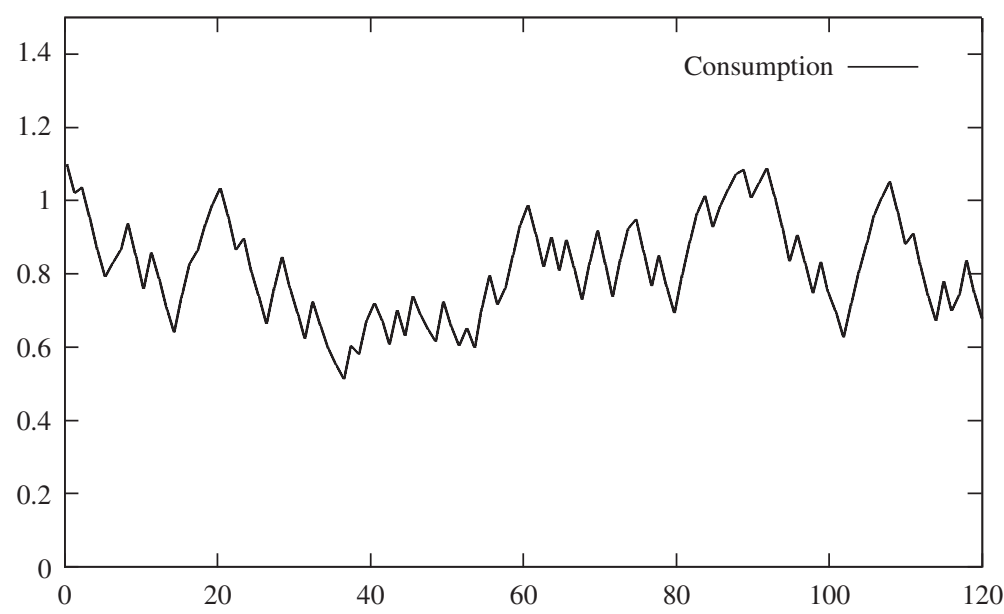

Fig. 4. Consumption at $\gamma=-1.0, \beta=0.97$.

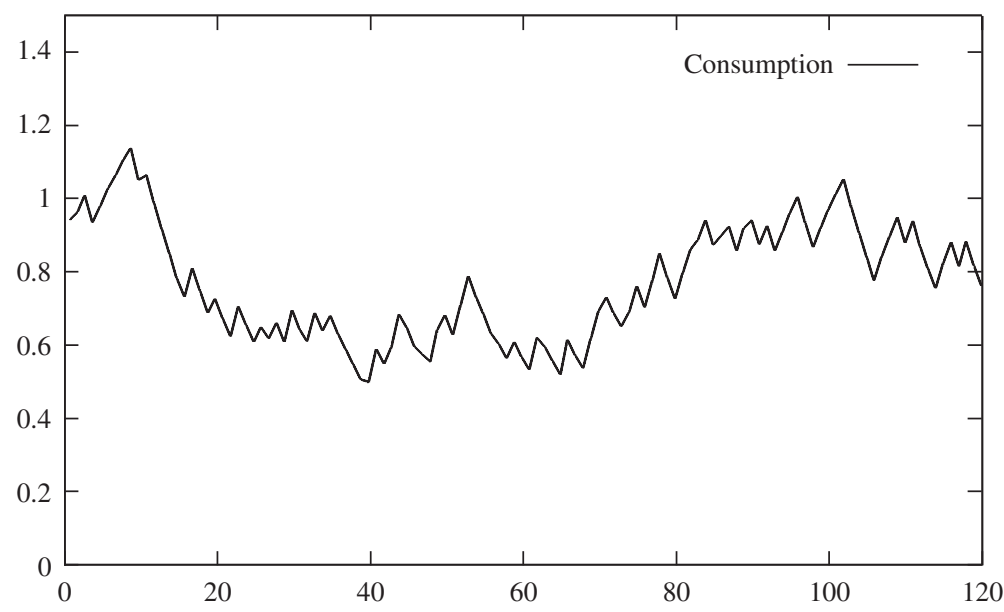

Fig. 5. Consumption at $\gamma=-1.0, \beta=0.99$.

\section{Scaling and uncertainty}

In this section we present some scaling results that hold for this model. We will show an invariance principle for two types of scalings: one where the productivity parameters, $\theta_{i, s}$, are scaled, and one where the economy is expanded by replication. We then show the impact of uncertainty in multiplicative models, and why our parameterization of the Brock model produces the results that we have presented in this paper. We also show the precise difference between the asset prices and the equity premia in the Lucas and Brock asset pricing models. 


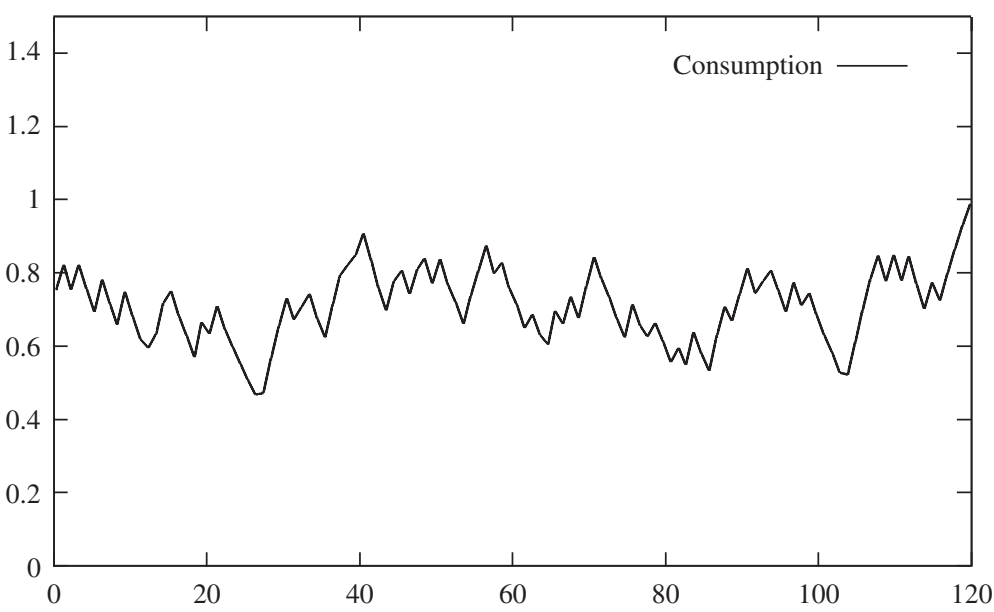

Fig. 6. Consumption at $\gamma=-2.0, \beta=0.95$.

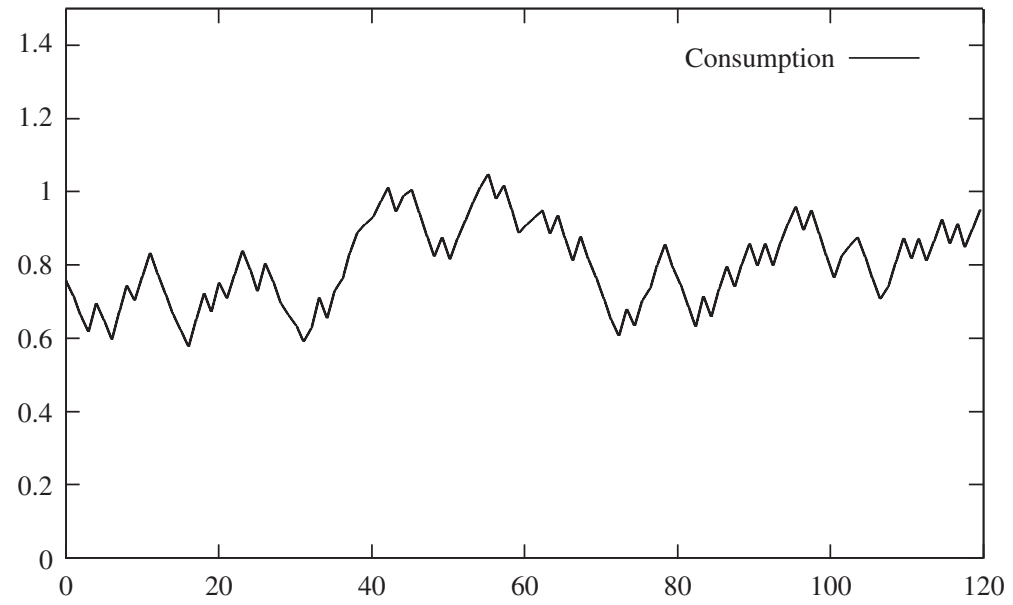

Fig. 7. Consumption at $\gamma=-2.0, \beta=0.97$.

\subsection{Scaling by replication}

Let the solution to the one firm problem

$$
\begin{aligned}
& \max \mathrm{E}\left[\sum_{t=0}^{\infty} \beta^{t} u\left(c_{t}\right)\right] \\
& c_{t}+x_{t+1}=y_{t}, \quad t=0,1, \ldots \\
& y_{t}=f\left(x_{t}, \xi_{t}\right), \quad t=1,2, \ldots
\end{aligned}
$$




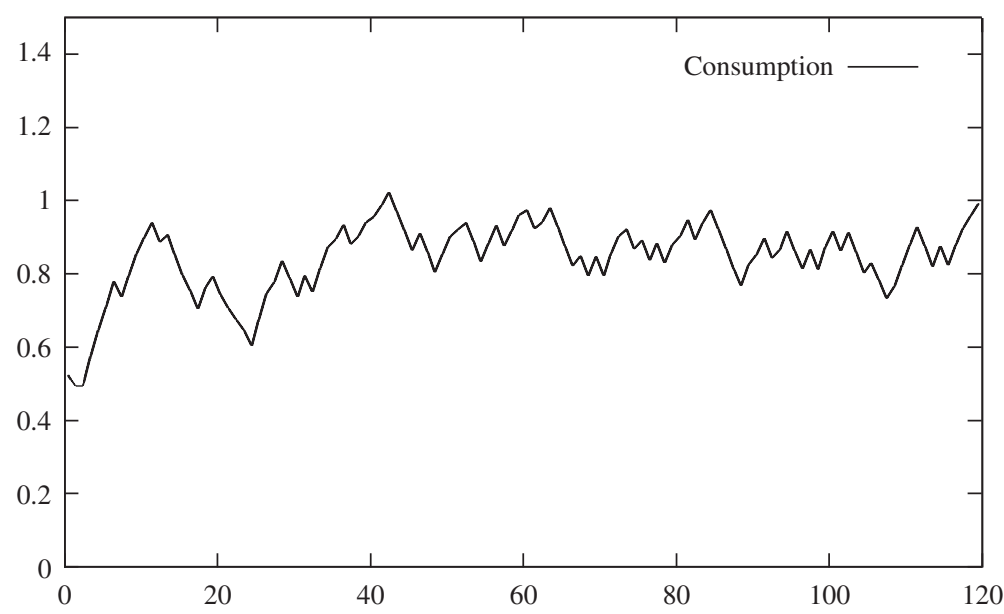

Fig. 8. Consumption at $\gamma=-2.0, \beta=0.99$.

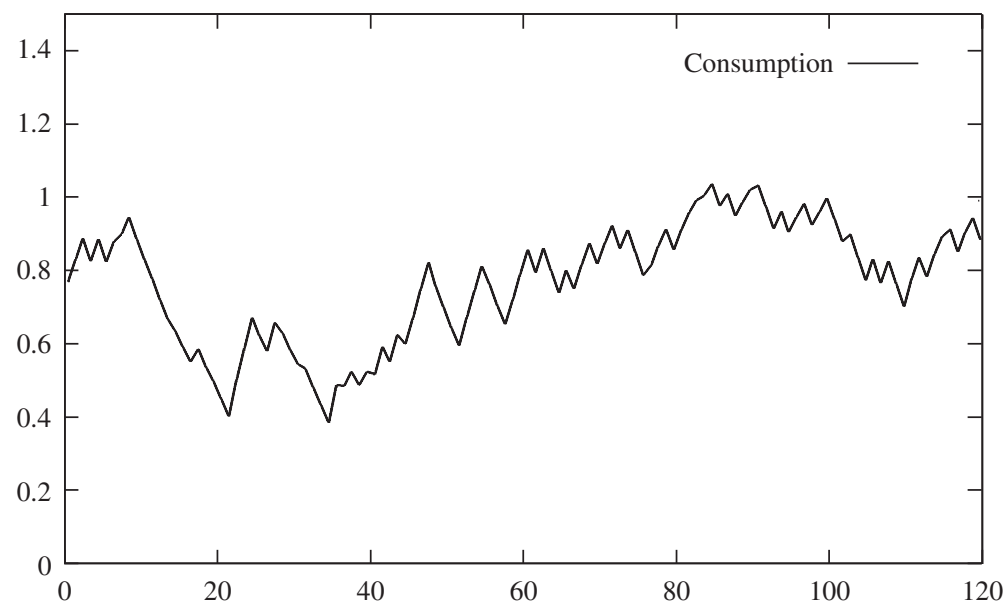

Fig. 9. Consumption at $\gamma=-3.0, \beta=0.95$.

be $x_{t}=h\left(y_{t}\right)$. Now consider the following two firm problem:

$$
\begin{aligned}
\max & \mathrm{E}\left[\sum_{t=0}^{\infty} \beta^{t} u\left(c_{t}\right)\right] \\
& c_{t}+x_{1, t+1}+x_{2, t+1}=y_{t}, \quad t=0,1, \ldots \\
& y_{t}=f\left(x_{1, t}, \xi_{t}\right)+f\left(x_{2, t}, \xi_{t}\right), \quad t=1,2, \ldots,
\end{aligned}
$$

where the two production functions both have the same functional form as in the one firm case. Since the utility function is a concave function of consumption, and the production function is a concave function of input, from the first order conditions it 


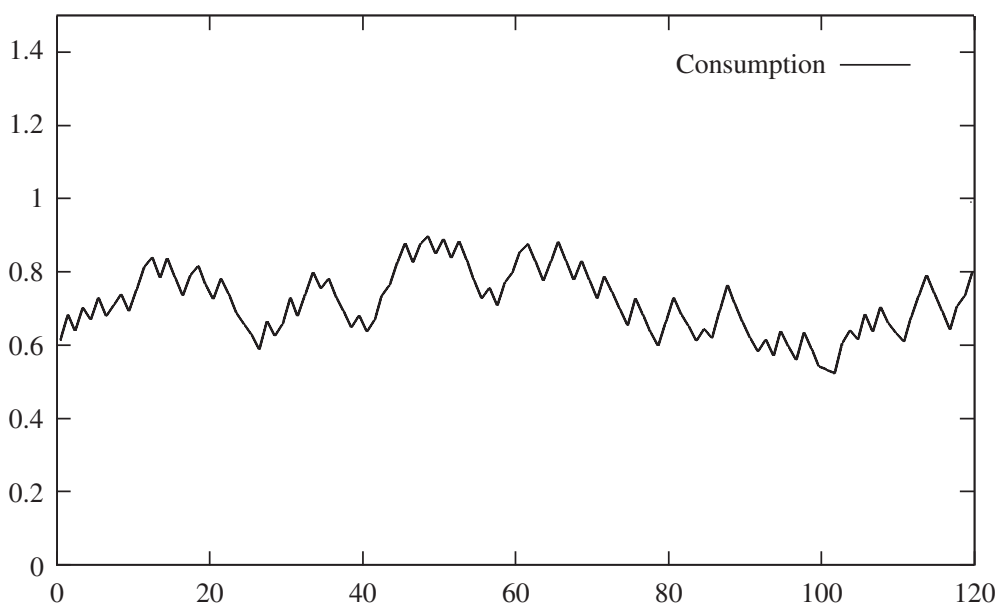

Fig. 10. Consumption at $\gamma=-3.0, \beta=0.97$.

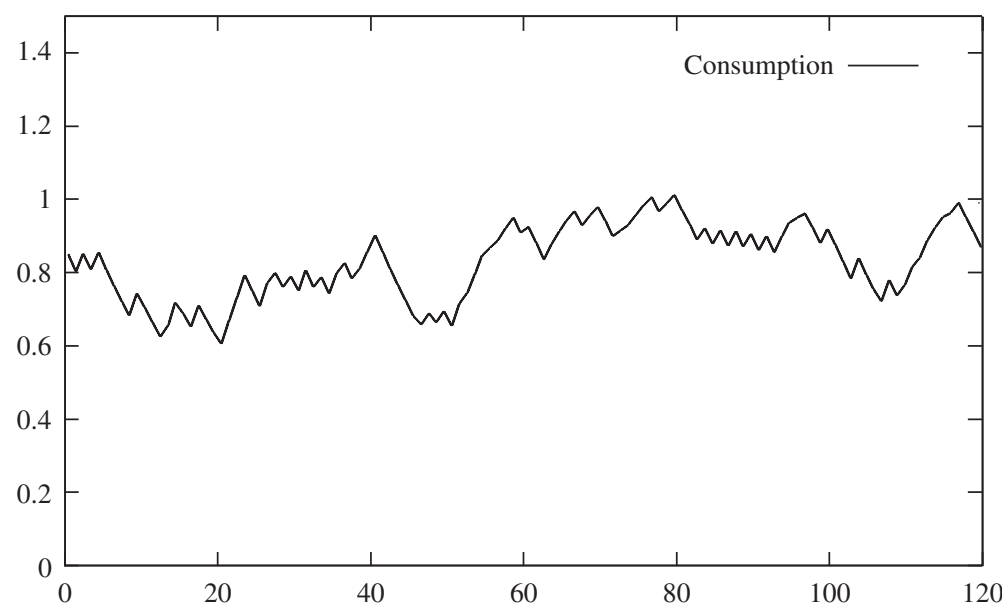

Fig. 11. Consumption at $\gamma=-3.0, \beta=0.99$.

is the case that the optimal investments in the two firms satisfy

$$
x_{1, t}=x_{2, t} \text {. }
$$

Let us call this common value $z_{t}$. Thus, the solution to the two firm problem is equivalent to

$$
\begin{aligned}
\max & \mathrm{E}\left[\sum_{t=0}^{\infty} \beta^{t} u\left(c_{t}\right)\right] \\
& c_{t}+2 z_{t+1}=y_{t}, \quad t=0,1, \ldots \\
y_{t} & =2 f\left(z_{t}, \xi_{t}\right), \quad t=1,2, \ldots
\end{aligned}
$$




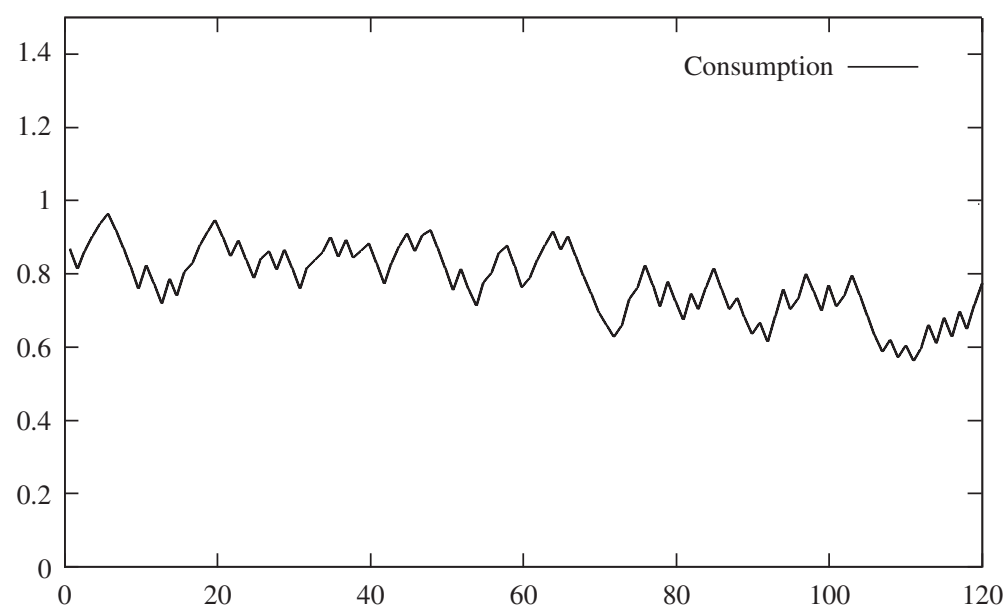

Fig. 12. Consumption at $\gamma=-4.0, \beta=0.95$.

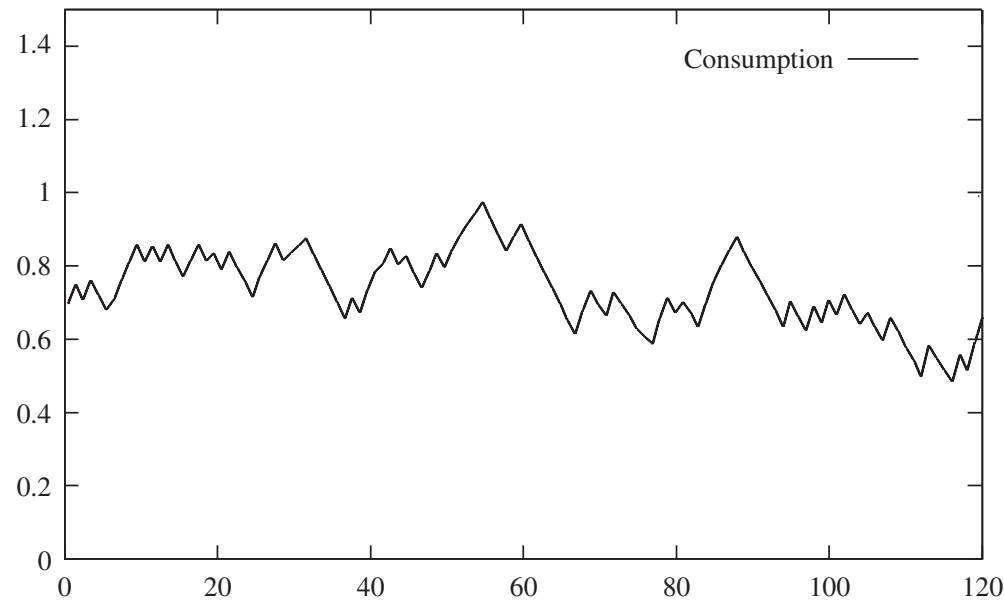

Fig. 13. Consumption at $\gamma=-4.0, \beta=0.97$.

Now define

$$
\tilde{c}_{t}=\frac{1}{2} c_{t}, \quad \tilde{y}_{t}=\frac{1}{2} y_{t}
$$

and this equivalent problem becomes

$$
\begin{aligned}
& \max \mathrm{E} {\left[\sum_{t=0}^{\infty} \beta^{t} u\left(2 \tilde{c}_{t}\right)\right] } \\
& \tilde{c}_{t}+z_{t+1}=\tilde{y}_{t}, \quad t=0,1, \ldots \\
& \tilde{y}_{t}=f\left(z_{t}, \xi_{t}\right), \quad t=1,2, \ldots .
\end{aligned}
$$




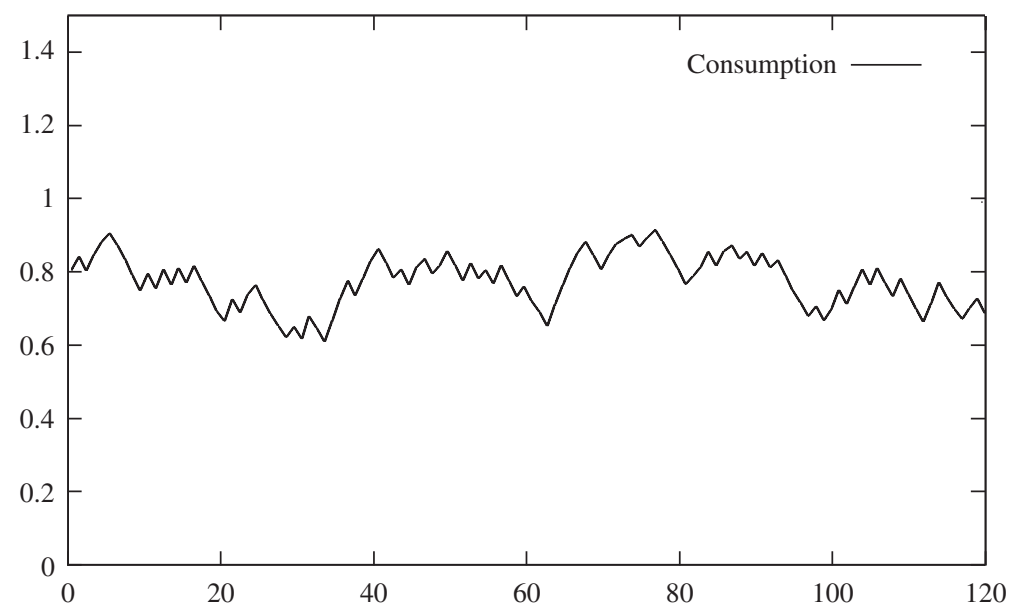

Fig. 14. Consumption at $\gamma=-4.0, \beta=0.99$.

Note the similarity with the one firm problem at the beginning of this section. Now this is as far as we can push the scaling result, and we see that indeed enlarging the economy by replication will have, in general, an impact on the result. However, for the parameterization in this paper the utility function is of the form $u(c)=c^{\gamma}$ and so

$$
\mathrm{E}\left[\sum_{t=0}^{\infty} \beta^{t} u\left(2 \tilde{c}_{t}\right)\right]=\mathrm{E}\left[\sum_{t=0}^{\infty} \beta^{t} 2^{\gamma} \tilde{c}_{t}^{\gamma}\right]=2^{\gamma} \mathrm{E}\left[\sum_{t=0}^{\infty} \beta^{t} u\left(\tilde{c}_{t}\right)\right]
$$

and so for this utility function, the two firm problem has the same solution as

$$
\begin{aligned}
\max & \mathrm{E}\left[\sum_{t=0}^{\infty} \beta^{t} u\left(\tilde{c}_{t}\right)\right] \\
& \tilde{c}_{t}+z_{t+1}=\tilde{y}_{t}, \quad t=0,1, \ldots \\
\tilde{y}_{t} & =f\left(z_{t}, \xi_{t}\right), \quad t=1,2, \ldots .
\end{aligned}
$$

Thus, the optimal policy functions are the same as for the one firm case which means that the equity premium (among other things) is invariant to scaling by replication.

\subsection{Scaling the $\boldsymbol{\theta}_{i, s}$ parameters}

Consider scaling the productivity parameters, $\theta_{i, s}$, as follows:

$$
\tilde{\theta}_{i, s}=A^{\alpha_{i, s}-1} \theta_{i, s}
$$


where $A>0$. The total output is

$$
\begin{aligned}
y & =\sum_{i}^{n}\left[\tilde{\theta}_{i, s} x_{i, s}^{\alpha_{i, s}}+\left(1-\delta_{i, s}\right) x_{i, s}\right] \\
& =\sum_{i}^{n}\left[A^{\alpha_{i, s}-1} \theta_{i, s} x_{i, s}^{\alpha_{i, s}}+\left(1-\delta_{i, s}\right) x_{i, s}\right] \\
& =\sum_{i}^{n}\left[A^{-1} \theta_{i, s}\left(A x_{i, s}\right)^{\alpha_{i, s}}+\left(1-\delta_{i, s}\right) x_{i, s}\right] .
\end{aligned}
$$

By multiplying both side of this last equality by $A$ we get

$$
A y=\sum_{i}^{n}\left[\theta_{i, s}\left(A x_{i, s}\right)^{\alpha_{i, s}}+\left(1-\delta_{i, s}\right) A x_{i, s}\right] .
$$

Therefore, if we scale the dynamic optimization equation

$$
A c_{t}+A x_{t+1}=A y_{t}
$$

and follow the reasoning above for the case that the utility function is of the form $u(c)=c^{\gamma}$, we readily see that the solution will be invariant to this rescaling as well.

\subsection{The real impact of production uncertainty}

Consider the Bellman equation for the growth model (2.1)

$$
V(y)=\max _{\left\{x_{i}\right\}}\left\{u\left(y-\sum_{i=1}^{n} x_{i}\right)+\beta \mathrm{E}\left[V\left(\sum_{i=1}^{n} f_{i}\left(x_{i}, \Xi\right)\right)\right]\right\}
$$

for which the first order conditions are

$$
u^{\prime}\left(y-\sum_{i=1}^{n} x_{i}\right)=\beta \mathrm{E}\left[V^{\prime}\left(\sum_{i=1}^{n} f_{i}\left(x_{i}, \Xi\right)\right) f_{j}^{\prime}\left(x_{j}, \Xi\right)\right], \quad j=1, \ldots, n
$$

which in turn implies that for all $j$ and $k$

$$
\mathrm{E}\left[V^{\prime}\left(\sum_{i=1}^{n} f_{i}\left(x_{i}, \Xi\right)\right) f_{j}^{\prime}\left(x_{j}, \Xi\right)\right]=\mathrm{E}\left[V^{\prime}\left(\sum_{i=1}^{n} f_{i}\left(x_{i}, \Xi\right)\right) f_{k}^{\prime}\left(x_{k}, \Xi\right)\right] \text {. }
$$

From this, it is clear that if the uncertainty is multiplicative, so that $f_{i}\left(x_{i}, \xi\right)=\xi f_{i}\left(x_{i}\right)$, then for all firms

$$
f_{i}^{\prime}\left(x_{i}\right)=f_{j}^{\prime}\left(x_{j}\right) \text {. }
$$

Thus, the marginal products of all firms are equal, regardless of the shock. So uncertainty only affects the overall level of output, and not the disaggregated investment decisions. Put another way, under these conditions we can construct a technology set that depends only on the level of aggregate savings, and not on the risk preferences of the consumer. For a given level of investment, $x$, solve Eq. (5.2) 
subject to $\sum x_{i}=x$, and define

$$
f(x)=\sum_{i=1}^{n} f_{i}\left(x_{i}\right) \text {. }
$$

Then we can reduce the problem to a one firm problem with the (random) production function, $\Xi f(x)$. In this case, there is very little equity premium unless other factors are adjusted or taken into account, e.g., a very high degree of relative risk aversion, habit persistence in consumption, etc.

Finally, let us look at a special case of the parameterization that we have chosen: the total output from Eq. (4.2) is of the special form

$$
y_{s, t+1}=\sum_{i=1}^{n} f_{i}\left(x_{i}, \xi\right)=\sum_{i=1}^{n}\left[\theta_{s} x_{i t}^{\alpha_{i}}+\left(1-\delta_{i}\right) x_{i t}\right] .
$$

Note that the $\alpha_{i}$ and $\delta_{i}$ parameters are not random, and the $\theta_{\mathrm{s}}$ shock is common to all firms. In this case Eq. (5.1) can be rewritten as

$$
\alpha_{j} x_{j}^{\alpha_{j}-1}-\alpha_{k} x_{k}^{\alpha_{k}-1}=\left(\delta_{k}-\delta_{j}\right) \frac{\mathrm{E}\left[V^{\prime}\left(\sum_{i}\left[\Theta x_{i}^{\alpha_{i}}+\left(1-\delta_{i}\right) x_{i}\right]\right)\right]}{\mathrm{E}\left[V^{\prime}\left(\sum_{i}\left[\Theta x_{i}^{\alpha_{i}}+\left(1-\delta_{i}\right) x_{i}\right]\right) \Theta\right]} .
$$

Note that the ratio on the right-hand side of this equation is a function of $x=\sum x_{i}$ (as well as the particular form of the utility function). Call this term

$$
\zeta_{u}(x)=\frac{\mathrm{E}\left[V^{\prime}\left(\sum\left[\Theta x_{i}^{\alpha_{i}}+\left(1-\delta_{i}\right) x_{i}\right]\right)\right]}{\mathrm{E}\left[V^{\prime}\left(\sum\left[\Theta x_{i}^{\alpha_{i}}+\left(1-\delta_{i}\right) x_{i}\right]\right) \Theta\right]},
$$

where the subscript $u$ emphasizes the dependence on the particular utility function. Then Eq. (5.3) is

$$
\alpha_{j} x_{j}^{\alpha_{j}-1}-\alpha_{k} x_{k}^{\alpha_{k}-1}=\left(\delta_{k}-\delta_{j}\right) \zeta_{u}(x) .
$$

Now if $\delta_{k}=\delta_{j}$, then we have the same situation as above. There is a single technology that we can construct which is independent of the utility function. The shocks do not impact the marginal product of the technology in a significant way. Even without the equality of depreciation rates, Eq. (5.4) shows that what matters is the level of investment, $x$, and not the distributional aspects of the shock.

What these results show is that for the case that there is only systematic shocks and no idiosyncratic shocks, the model behaves as a one firm model. What our numerical results show is that the presence of idiosyncratic shocks along with systematic shocks matter in the sense that the equity premium is higher when there are more sources of idiosyncratic shocks. ${ }^{29}$

\footnotetext{
${ }^{29}$ Turnovsky and Bianconi (2005) also find that idiosyncratic shocks play an important role in the risk premium on capital. E.g., on p. 27, 'If the reduction in aggregate risk is accompanied by an approximate doubling in the reduction of idiosyncratic risk from 0.15 to 0.10 , then the gains from the stabilization of the aggregate risk increase to between $1.3 \%$ to $2.8 \%$, depending upon the degree of risk aversion.' And on p. 29 they state, 'In the presence of idiosyncratic risk, the mean return on capital and the savings rate are both nonmonotonically related to the degree of risk aversion.' In other work, Saito (1998) examined the effect of idiosyncratic shocks on the risk free rate of return, and found that 'Assuming an empirically
} 


\subsection{Brock vs Lucas asset prices}

Consider the difference in the asset prices that are generated by the Lucas (1978) model and the Brock (1982) model. In particular, consider a consumption process, $\left\{c_{t}\right\}$, that is generated by the model in Sections 2 and 3, and then compare the asset prices that are generated by the Lucas with the same consumption process.

In the Lucas model all output is consumed $\left(c_{t}=y_{t}\right)$ and the asset price sequence, $\left\{\tilde{P}_{i t}\right\}$, satisfies

$$
\tilde{P}_{i t} u^{\prime}\left(c_{t}\right)=\beta \mathrm{E}_{t}\left[u^{\prime}\left(c_{t+1}\right)\left(c_{i, t+1}+\tilde{P}_{i, t+1}\right)\right] .
$$

Using the notation of Section 3, let

$$
\tilde{M}_{t}=\sum_{i} \tilde{P}_{i t}
$$

and sum equation (5.5) over the firms to get

$$
\tilde{M}_{t} u^{\prime}\left(c_{t}\right)=\beta \mathrm{E}_{t}\left[u^{\prime}\left(c_{t+1}\right)\left(c_{t+1}+\tilde{M}_{t+1}\right)\right] .
$$

Sum equation (3.6) over the firms to get the market price sequence

$$
\begin{aligned}
M_{t} u^{\prime}\left(c_{t}\right) & =\beta \mathrm{E}_{t}\left[u^{\prime}\left(c_{t+1}\right)\left(\pi_{t+1}+M_{t+1}\right)\right] \\
& =\beta \mathrm{E}_{t}\left[u^{\prime}\left(c_{t+1}\right)\left(y_{t+1}-\sum_{i} f_{i}^{\prime}\left(x_{i t}, \xi_{t}\right) x_{i t}+M_{t+1}\right)\right] \\
& =\beta \mathrm{E}_{t}\left[u^{\prime}\left(c_{t+1}\right)\left(c_{t+1}+M_{t+1}\right)\right]+\beta \mathrm{E}_{t}\left[u^{\prime}\left(c_{t+1}\right) x_{t+1}\right]-u^{\prime}\left(c_{t}\right) x_{t},
\end{aligned}
$$

where we use Eqs. (2.2) and (2.7) to get Eq. (5.9). A comparison of Eqs. (5.6) and (5.9) shows that for these asset prices to have the same value then

$$
u^{\prime}\left(c_{t}\right) x_{t}=\beta \mathrm{E}_{t}\left[u^{\prime}\left(c_{t+1}\right) x_{t+1}\right]
$$

must hold. However, this is not a necessary condition.

Next, look at the appendix in (Brock, 1982, pp. 36-39), and consider his equation (A5.12) summed over the firms. The market value of the firms satisfies

$$
\begin{aligned}
u^{\prime}\left(c_{t}\right) V_{t} & =\mathrm{E}_{t}\left[u^{\prime}\left(c_{t+1}\right)\left(y_{t+1}-x_{t+1}+V_{t+1}\right)\right] \\
& =\mathrm{E}_{t}\left[u^{\prime}\left(c_{t+1}\right)\left(c_{t+1}+V_{t+1}\right)\right]
\end{aligned}
$$

which is precisely the Lucas formula for the market value of the firms! Heuristically, the only thing that matters to the consumer is his/her total wealth, which in the main part of the Brock article is $M_{t}+x_{t}$, since $\mathrm{s} /$ he owns the firms and the capital stock that the firms rent. In the appendix of the Brock article, the firms own the capital stock so the consumer's wealth is $V_{t}$. It should be the case that $V_{t}=M_{t}+x_{t}$. Here is a proof.

(footnote continued) reasonable magnitude of idiosyncratic shocks $\left(\sigma_{h}\right)$, we have shown that the prediction of risk-free rates is improved considerably.' (P. 775.) 
Compute the difference

$$
\begin{aligned}
\tilde{M}_{t}-M_{t}= & \beta E_{t}\left[\frac{u^{\prime}\left(c_{t+1}\right)}{u^{\prime}\left(c_{t}\right)}\left(c_{t+1}+\tilde{M}_{t+1}-y_{t+1}+f^{\prime}\left(x_{t}, \xi_{t}\right) x_{t}-M_{t+1}\right)\right] \\
= & \beta \mathrm{E}_{t}\left[\frac{u^{\prime}\left(c_{t+1}\right)}{u^{\prime}\left(c_{t}\right)}\left(\tilde{M}_{t+1}-M_{t+1}\right)\right] \\
& -\beta \mathrm{E}_{t}\left[\frac{u^{\prime}\left(c_{t+1}\right)}{u^{\prime}\left(c_{t}\right)}\left(x_{t+1}-f^{\prime}\left(x_{t}, \xi_{t}\right) x_{t}\right)\right] \\
= & \beta \mathrm{E}_{t}\left[\frac{u^{\prime}\left(c_{t+1}\right)}{u^{\prime}\left(c_{t}\right)}\left(\tilde{M}_{t+1}-M_{t+1}\right)\right]-\beta \mathrm{E}_{t}\left[\frac{u^{\prime}\left(c_{t+1}\right)}{u^{\prime}\left(c_{t}\right)} x_{t+1}\right]+x_{t} .
\end{aligned}
$$

Rearrange the terms in Eq. (5.14) to get

$$
\tilde{M}_{t}-M_{t}-x_{t}=\beta \mathrm{E}_{t}\left[\frac{u^{\prime}\left(c_{t+1}\right)}{u^{\prime}\left(c_{t}\right)}\left(\tilde{M}_{t+1}-M_{t+1}-x_{t+1}\right)\right] .
$$

By transversality, the left-hand side must be zero, so

$$
\tilde{M}_{t}=M_{t}+x_{t} \text {. }
$$

We can follow the same line of argument to get the relationship between the asset prices of the individual firms

$$
\tilde{P}_{i t}=P_{i t}+x_{i t}
$$

We now have the difference between Lucas and Brock asset prices. Next, the equity premium in the two models is

$$
\begin{aligned}
& \tilde{e}_{t}=\mathrm{E}_{t}\left[\frac{\tilde{M}_{t+1}}{\tilde{M}_{t}}\right]-\frac{1}{B_{t, t+1}}, \\
& e_{t}=\mathrm{E}_{t}\left[\frac{M_{t+1}}{M_{t}}\right]-\frac{1}{B_{t, t+1}},
\end{aligned}
$$

where the bond price, $B_{t, t+1}$, is given by Eq. (3.10). Compute the difference in the equity premia and use Eq. (5.16) to get

$$
\begin{aligned}
\tilde{e}_{t}-e_{t} & =\mathrm{E}_{t}\left[\frac{\tilde{M}_{t+1}}{\tilde{M}_{t}}-\frac{M_{t+1}}{M_{t}}\right] \\
& =\mathrm{E}_{t}\left[\frac{M_{t+1}+x_{t+1}}{M_{t}+x_{t}}-\frac{M_{t+1}}{M_{t}}\right] \\
& =\mathrm{E}_{t}\left[\frac{M_{t} x_{t+1}-M_{t+1} x_{t}}{M_{t}\left(M_{t}+x_{t}\right)}\right] \\
& =\left(\frac{x_{t}}{M_{t}+x_{t}}\right) \mathrm{E}_{t}\left[\frac{x_{t+1}}{x_{t}}-\frac{M_{t+1}}{M_{t}}\right] .
\end{aligned}
$$




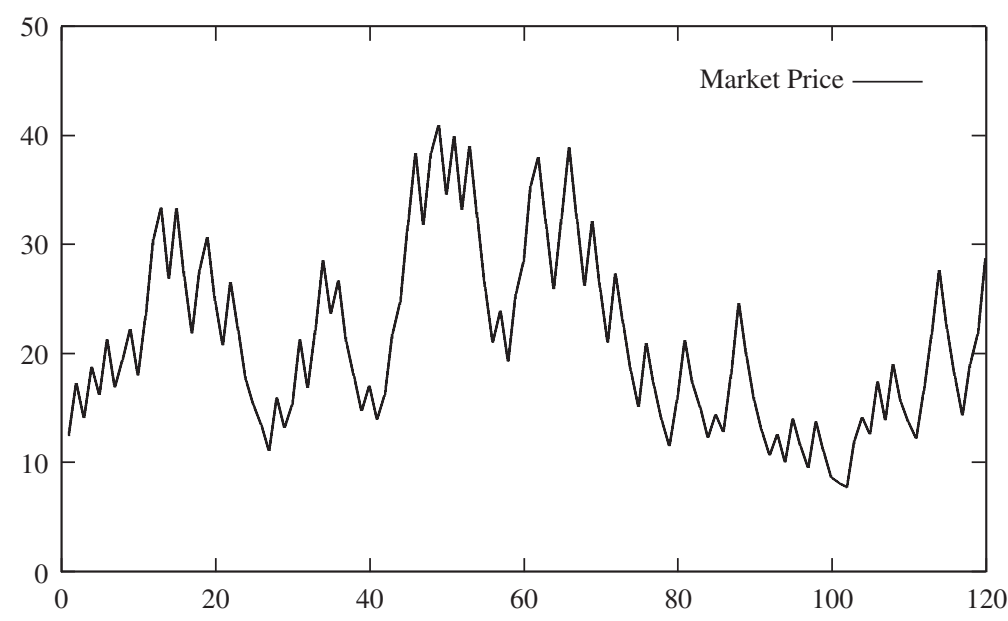

Fig. 15. Market price at $\gamma=-3.0, \beta=0.97$.

Now Eq. (5.23) is quite interesting. For example, when the optimal investment functions and the pricing functions are all linear in output, $y$, then

$$
\frac{x_{t+1}}{x_{t}}=\frac{y_{t+1}}{y_{t}}=\frac{M_{t+1}}{M_{t}}
$$

in which case

$$
\tilde{e}_{t}-e_{t}=0 .
$$

This is the case when $u(c)=\ln (c)$ and $f_{i}(x, \xi)=\xi A_{i} x^{\alpha}$. So it is no wonder that this whole literature has taken the view that 'production does not add anything' to the equity premium. However, for models where the policy and pricing functions are not linear, Eq. (5.23) is not in general zero, and so there is a difference in the equity premia in the two models, in spite of the fact that the real side is the same in both models!

\section{Conclusion}

In this paper, numerical results point to the fact that by including production directly into the model we can obtain equity premia that are more consistent with US data than can be had from models that are based on consumption alone.

It is also clear from both the data and simulations, that the typical application of Brock's asset pricing model has a number of shortcomings that need to be addressed before it might become a widely accepted basis for macro economic research. ${ }^{30}$ From

\footnotetext{
${ }^{30}$ Although the model is widely cited, the only numerical solution is the one in Akdeniz and Dechert (1997) which was also used in Akdeniz (2000). Judd (1992) has a solution for the Brock and Mirman (1972) model.
} 


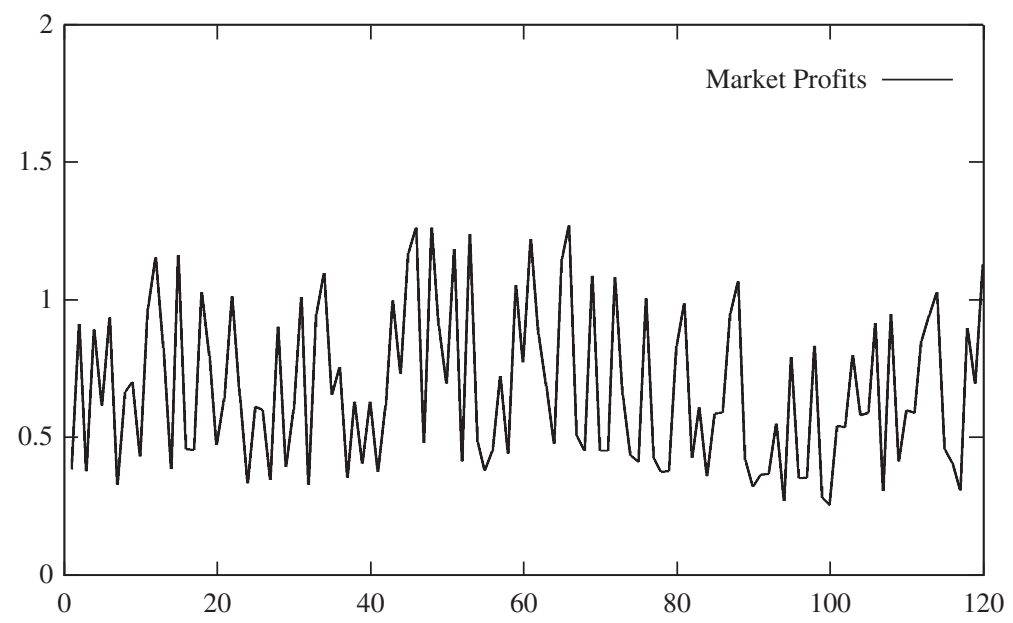

Fig. 16. Market profits at $\gamma=-3.0, \beta=0.97$.

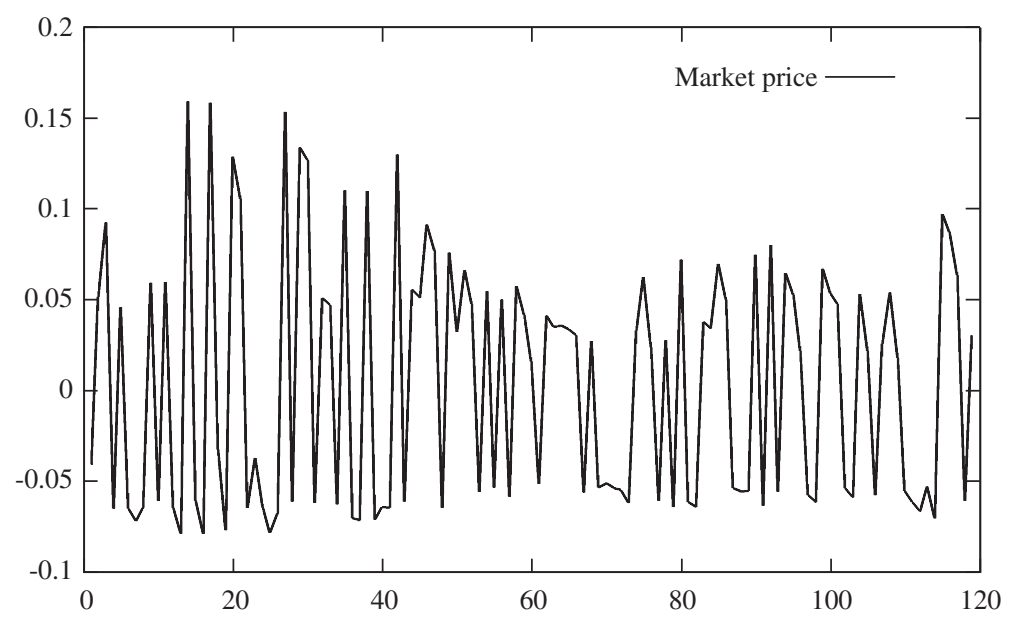

Fig. 17. Changes in market price at $\gamma=-3.0, \beta=0.97$.

a macro economic point of view, one shortcoming is that the model does not include growth. While one can view it as a 'detrended' model, most macro economists build growth into their models, and would expect to see it in this one as well. Another problem with the model can be seen from Figs. 15 and $16 .{ }^{31}$ Market prices and profits do not follow the patterns in these figures. One reason for this is the iid nature of the shocks over time. To the extent that random shocks is a reasonable model for

\footnotetext{
${ }^{31}$ Figs. 15 and 16 show the price and profit series for the market portfolio, while Figs. 17 and 18 show the percentage changes in the two series.
} 


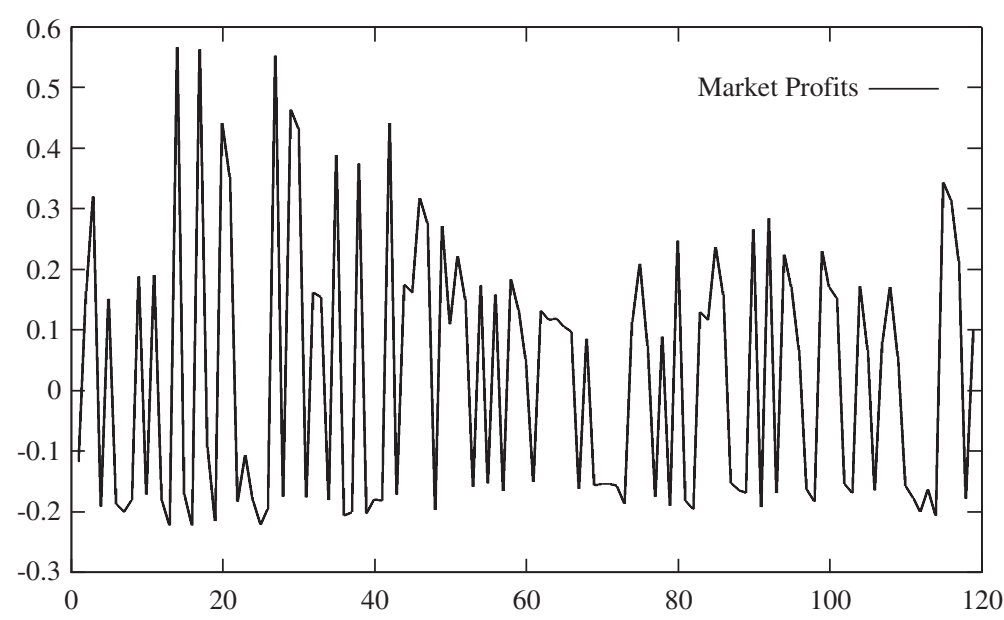

Fig. 18. Changes in market profits at $\gamma=-3.0, \beta=0.97$.

the fluctuations in output, surely there is substantial serial correlation in them. This means that Brock's model should, at the very least, use a Markov model for the systematic shocks. ${ }^{32}$ These shortcomings are not inherent in Brock's model, but are rather complications which add to the computational complexity of implementing a numerical solution of the model. This explains, in part, why the model has not been extensively used.

\section{Acknowledgments}

We thank W.A. Brock for many helpful comments and encouragement. We also thank S. Durlauf and R. Manuelli for their comments and insights. All errors of omission and commission are our responsibility alone.

\section{References}

Akdeniz, L., 2000. Risk and return in a dynamic general equilibrium model. Journal of Economic Dynamics and Control 24, 1079-1096.

Akdeniz, L., Dechert, W.D., 1997. Do CAPM results hold in a dynamic economy? A numerical analysis. Journal of Economic Dynamics and Control 21, 981-1003.

Black, F., 1995. Exploring General Equilibrium. MIT Press, Cambridge, MA.

\footnotetext{
${ }^{32}$ Note that Brock's model with iid shocks does exhibit serial correlation in the output and consumption processes. This is due to the 'spillover' effects of savings. I.e., when output is high, a greater fraction of it is used as investment, which somewhat insulates the economy from a bad shock in the next period. A Markov series for the shocks would emphasize this effect and produce longer intervals between peaks and troughs in output. Also, the effect of crashes being steeper than recoveries can be incorporated with Markov shocks, but not with iid shocks. See Danthine and Donaldson (1986) for a model of asset prices where the shocks are modeled as a Markov process in the output series, $Y_{t}$.
} 
Boldrin, M., Christiano, L.J., Fisher, J.D.M., 2001. Habit persistence, asset returns and the business cycle. American Economic Review 91, 149-166.

Brock, W.A., 1979. An integration of stochastic growth theory and the theory of finance - part i: the growth model. In: Green, J., Scheinkman, J. (Eds.), General Equilibrium, Growth And Trade. Academic Press, New York, pp. 165-192.

Brock, W.A., 1982. Asset prices in a production economy. In: McCall, J.J. (Ed.), The Economics of Information and Uncertainty. University of Chicago Press, Chicago, pp. 1-46.

Brock, W.A., Mirman, L., 1972. Optimal economic growth and uncertainty: the discounted case. Journal of Economic Theory 4, 479-513.

Brock, W.A., Turnovsky, S.J., 1981. The analysis of macroeconomic policies in perfect foresight equilibrium. International Economic Review 22 (1), 179-209.

Campbell, J.Y., 2003. Consumption-based asset pricing. In: Constantinides, G., Harris, M., Stulz, R., (Eds.). Handbook of the Economics of Finance, vol. 1B (Chapter 13). Elsevier.

Campbell, J.Y., Cochrane, J.H., 1999. By force of habit: a consumption-based explanation of aggregate stock market behavior. Journal of Political Economy 107, 205-251.

Constantinides, G., 1990. Habit formation: a resolution of the equity premium puzzle. Journal of Political Economy 98, 519-543.

Cooley, T.F., Prescott, E.C., 1995. Economic growth and business cycles. In: Cooley, T.F. (Ed.), Frontiers of Business Cycle Research. Princeton University Press, Princeton, NJ, pp. 1-38 (Chapter 1).

Danthine, J.-P., Donaldson, J.B., 1986. Inflation and asset prices in an exchange economy. Econometrica 54, 585-606.

Geweke, J., 1999. Computational Experiments and Reality. University of Iowa, Iowa.

Judd, K.L., 1992. Projection methods for solving aggregate growth models. Journal of Economic Theory 58, 410-452.

Judd, K.L., 1995. Computational Economics and Economic Theory: Substitutes or Complements? Hoover Institute, Stanford University, May 1995.

Judd, K.L., 1998. Computational Economics. MIT Press, Cambridge, MA.

Kocherlakota, N.R., 1996. The equity premium: It's still a puzzle. Journal of Economic Literature XXXIV, 42-71.

Lucas, R.E., 1978. Asset prices in an exchange economy. Econometrica 46, 1429-1445.

McGrattan, E.R., Prescott, E., 2001. Taxes, regulations, and asset prices, Working Paper 610, Federal Reserve Bank of Minneapolis.

Mehra, R., 1984. Recursive competitive equilibrium: a parametric example. Economics Letters 16, 273-278.

Mehra, R., Prescott, E.C., 1985. The equity premium: a puzzle. Journal of Monetary Economics 15, 145-161.

Saito, M., 1998. A simple model of incomplete insurance: the case of permanent shocks. Journal of Economic Dynamics and Control 22, 763-777.

Turnovsky, S.J., Bianconi, M., 2005. The welfare gains from stabilization in a stochastically growing economy with idiosyncratic shocks and flexible labor supply. Macroeconomic Dynamics 9, 321-357.

Weitzman, M.L., 2004. The Bayesian Family of Equity Non-Puzzles. Harvard University, Cambridge, MA. 